\title{
PELATIHAN KERAJINAN TAS RAJUT BAGI REMAJA PUTRI DI DESA MAMBALAN
}

\author{
Masiah $^{1)}$, Siti Rabiatul Adawiyah ${ }^{1)}$ \\ 1)Program Studi Pendidikan Biologi, FSTT, Universitas Pendidikan Mandalika, Mataram, Indonesia \\ Corresponding author: Masiah \\ E-mail : masiah@ikipmataram.ac.id
}

\section{Diterima 6 April 2020, Disetujui 22 April 2020}

\begin{abstract}
ABSTRAK
Remaja putri adalah calon pembentuk generasi masa depan sehingga membekalinya dengan keterampilan tertentu menjadi sebuah keharusan sebagai langkah membangun ekonomi kreatif di masa mendatang, serta yang tidak kalah penting juga adalah menghindarkannya dari pergaulan yang tidak sehat. Salah satu langkah yang bisa dilakukan adalah dengan memberikan pelatihan berupa kerajinan tas rajut. Kegiatan positif ini dapat menjadikannya memiliki kesibukan positif disela-sela waktu sekolahnya. Produk kerajinan tas rajut ini sangat diminati oleh masyarakat, hal tersebut merupakan hal yang menjanjikan untuk ditekuni. Metode kegiatan yang dilakukan meliputi pembekalan dan pendampingan bagi beberapa mahasiswa (kegiatan ini melibatkan peran serta beberapa mahasiswa), sosialisai dan pendampingan membuat produk kerajinan tas rajut bagi remaja putri Desa Mambalan Kecamatan Gunung Sari LOBAR. Hasil kegiatan pengabdian meliputi; remaja desa Mambalan mempunyai bekal keterampilan untuk berwirausaha dan terciptanya produk kerajinan berupa tas rajut, selain itu kegiatan ini juga mendapat respon positif dari orang tua remaja yang menjadi peserta.
\end{abstract}

Kata kunci : tas rajut; remaja putri.

ABSTRACT
Adolescent girls are candidates for forming future generations so providing them with certain skills becomes a necessity as a step to build a creative economy in the future, and equally important is to avoid unhealthy relationships. One step that can be done is to provide training in the form of craft knitting bags. This positive activity can make him have a positive activity in the middle of his school time. This knitting bag handicraft product is in great demand by the public, it is a promising thing to pursue. The method of activities carried out included debriefing and mentoring for some students (this activity involved the participation of several students), socialization and assistance in making knitting bag handicraft products for young women in Mambalan Village, Gunung Sari Subdistrict, LOBAR. The results of community service activities include; Mambalan village adolescents have the provision of skills for entrepreneurship and the creation of handicraft products in the form of knitting bags, in addition to this activity also received a positive response from parents of teenagers who became participants.

Keyworda : knitting bag; young women.

\section{PENDAHULUAN}

Masa remaja adalah masa-masa yang sangat penting untuk membentuk pribadi masa depannya. Apabila pada masa-masa ini tidak diisi dengan kegiatan-kegiatan positif maka bisa jadi akan terjerumus kedalam hal-hal yang tidak bermanfaat seperti akan terjerumus kepada pernikahan dini. Pernikahan dini biasanya terjadi pada remaja-remaja yang mengisi waktu luangnya dengan sibuk berpacaran. Kasus pernikahan usia dini menjadi perhatian Badan Kependudukan dan Keluarga Berencana Nasional (BKKBN) NTB. Tahun 2016 tercatat sekitar $5 \%$ pernikahan dini terjadi di wilayah NTB, Kepala BKKBN NTB Lalu Makripuddin menjelaskan, angka pernikahan usia dini di NTB cukup tinggi se Indonesia. Bahkan NTB nomor dua setelah Jawa Barat, hal ini sangat memprihatinkan karena akan mengancam keselamatan ibu dan bayinya (lombokpost.net/2016/).

Pernikahan dini masih banyak dijumpai hingga sekarang. Sampai saat ini, masih sering kita dengar fenomena pernikahan dini tidak hanya di kalangan masyarakat adat saja akan tetapi telah merambah pelajar sekolah yang semestinya fokus menuntut ilmu dan mengembangkan bakat. Usia remaja menimbulkan berbagai masalah dari berbagai sisi seperti masa remaja yang ingin selalu mencoba-coba sesuatu yang menantang adrenalin, walaupun kadang mereka kurang 
mengetahui dampak akibat perbuatan tersebut dapat mempengaruhi masa depan mereka. Sedangkan pada saat persalinan dapat menimbulkan, persalinan lama, ketuban pecah dini, ketidakseimbangan kepala bayi dengan lebar panggul, persalinan premature, berat badan bayi lahir rendah dan perdarahan yang dapat mengancam keselamatan jiwa ibu maupun bayinya (Manuaba,2009).

Salah satu cara untuk menghindari kasus tersebut serta dapat dijadikan sebagai bekal bagi mereka untuk membangun kreativitasnya kini dan nanti, maka pelatihan keterampilan merajut dapat menjadi salah satu solusinya, dengan kegiatan ini diharapkan para remaja tidak memiliki waktu yang digunakan dalam hal yang tidak bermanfaat. Merajut (bahasa Inggris: knitting) adalah metode membuat kain, pakaian atau perlengkapan dari benang rajut. Berbeda dari menenun yang menyilangkan dua jajaran benang yang saling tegak lurus, merajut hanya menggunakan sehelai benang. Sebaris tusukan yang sudah selesai dipegang di salah satu jarum rajut sampai dimulainya tusukan yang baru. Merajut dapat dilakukan dengan tangan ataupun mesin. Ada berbagai jenis gaya dan teknik merajut. Teknik dasar dalam merajut adalah tusuk atas dan tusuk bawah. Tusuk atas dilakukan dengan cara mengaitkan benang dari arah depan, sementara tusuk bawah adalah mengait benang dari arah belakang.

Aktivitas merajut juga diketahui bermanfaat bagi kesehatan, meningkatkan suansana hati $(\mathrm{mood})$. Merajut merupakan sebuah proses berulang yang membutuhkan keterampilan fisik dan kognitif (Hosegood, 2009). Menurut Blanche (2007), merajut berorientasi pada proses dan produk. Proses berarti perajut terlibat dalam aktivitas dan produk berarti ada keluaran spesifik dari proses yang menciptakan kepuasan saat menyelesaikan aktivitas tersebut.

Kelompok sasaran program pengabdian ini adalah remaja-remaja yang ada di desa Mambalan. Di sini, remaja akan diberikan pengetahuan tentang pernikahan yang ideal agar tidak terjerumus kepada pernikahan dini, serta yang paling penting adalah akan diberikan pelatihan keterampilan merajut.

\section{METODE}

Sasaran utama kegiatan pengabdian ini adalah peran aktif remaja putri dalam mengisi waktu luang/disela-sela waktu sekolahnya. Adapun tahapan pelaksanaanya sebagai berikut.

1. Inisiasi program
Kegiatan ini meliputi perkenalan antara Tim dengan remaja putri Desa Mambalan yang sebelumnya sudah dikoordinasikan terlebih dahulu dengan koordinator lapangan yang ada di desa.

2. Sosialisasi kepada remaja putri terkait kegiatan yang akan dilaksanakan, tahapan ini diharapkan agar para remaja mempunyai kepedulian yang tinggi terhadap diri mereka saat ini dan di masa depan. Hal yang paling penting untuk diperhatikan bahwa, menikah di usia dini menimbulkan banyak kekwatiran baik dari segi kesehatan ibu dan anak, mental, maupun psikologinya. Sebaliknya, usia muda adalah usia yang cocok untuk memacu kreatifitas dan produktif dalam hal yang sifatnya positif.

3. Pendampingan merajut, pada tahapan ini dilakukan oleh Tim dan dibantu oleh beberapa mahasiswa yang sedari awal sudah dilibatkan dalam kegiatan pengabdian.

4. Evaluasi program

Evaluasi program bertujuan untuk mengetahui keterlaksanaan dan efektivitas program yang sedang dan telah dilaksanakan.

\section{HASIL DAN PEMBAHASAN}

Kegiatan KKN PPM ini telah dilaksanakan di desa Mambalan kecamatan Gunungsari Kabupaten Lombok Barat NTB. Desa Mambalan. Kegiatan ini dilaksanakan selama satu bulan. Berikut dijelaskan rincian kegiatannya.

\section{Persiapan dan Pembekalan}

Persiapan dimulai dengan memberikan pembekalan oleh tim dosen kepada mahasiswa yang ikut terlibat dalam kegiatan yang akan dilakukan. Pembekalan meliputi pembekalan materi dan praktek merajut.

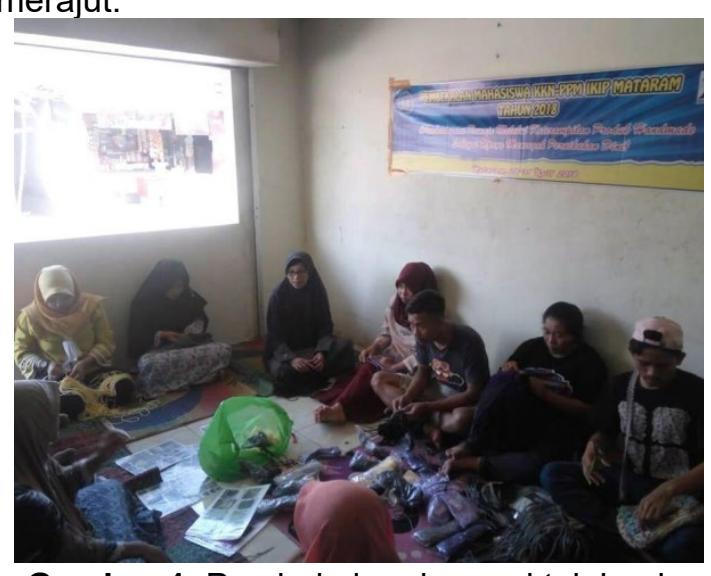

Gambar 1. Pembekalan dan praktek bagi mahasiswa yang ikut terlibat 


\section{Pelaksanaan Kegiatan}

Kegiatan awal dimulai dengan perkenalan antara Tim dengan remaja Desa Mambalan.
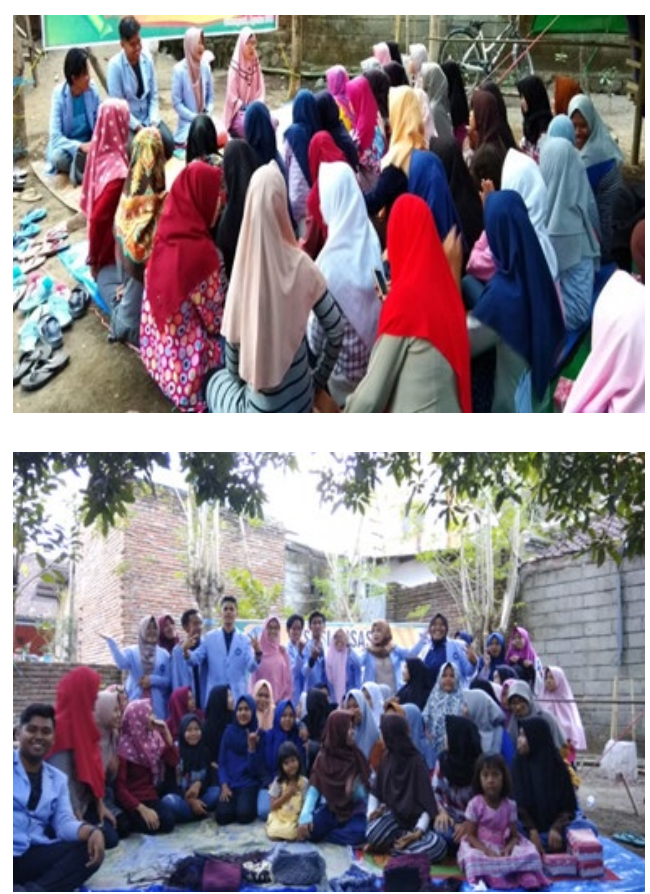

Gambar 2. Kegiatan sosialisasi kepada remaja desa Mambalan
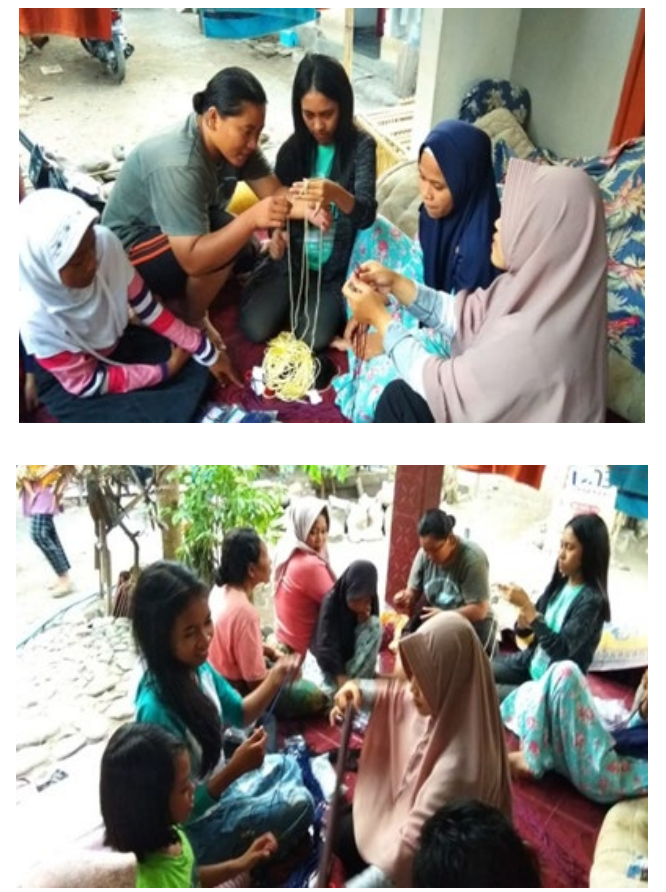

Gambar 3. Pelatihan remaja oleh mahasiswa dalam membuat tas.

Selajutnya memberikan sosialisasi kepada remaja terkait pernikahan dini dan memberikan motivasi untuk produktif diusianya. Dalam sosialisasi ini juga diperkenalkan produk tas rajut yang kemudian akan menjadi bagian dari pelatihan yang diberikan sehingga bisa menjadi pilihan remaja dalam mengisi waktu luang mereka. Setelah sosialisasi selanjutnya Tim memberikan pelatihan membuat tas rajut.

Pelatihan membuat tas diikuti oleh kurang lebih 30 orang remaja yang terdiri dari anak SLTP/Sederajat dan SLTA/Sederajat. Perekrutan peserta pelatihan berdasarkan tujuan utama program pengabdian yaitu agar kegiatan ini dapat menjadi wadah bagi mereka ke depan dalam berkreativitas, selain itu juga dengan adanya kegiatan ini dapat mencegah pernikahan dini, karena dengan mereka memiliki kesibukan yang bersifat positif di selasela waktu sekolah dapat dijadikan untuk menekuni keterampilan ini, dengan terisinya sela-sela waktu luang mereka, maka waktu untuk sekedar 'pacaran' menjadi tidak terbatas atau hampir tidak ada. Atas dasar demikanlah peserta yang boleh mengikuti pelatihan diprioritaskan bagi mereka yang berumur di bawah 16 tahun. Waktu pelatihan mengikuti waktu luang peserta yaitu pada sore hari dan hari libur sekolah. Dalam setiap pelatihan antusiasme remaja sangat tinggi, hal ini dapat dilihat dari keikutsertaan mereka yang hampir tidak pernah absen.

Produk tas talikur yang dihasilkan beraneka ragam, mulai dari tas selempengan panjang, pendek hingga tas tangan (handbag) dengan motif yang bermacam-macam sehingga menambah warna produk mereka.

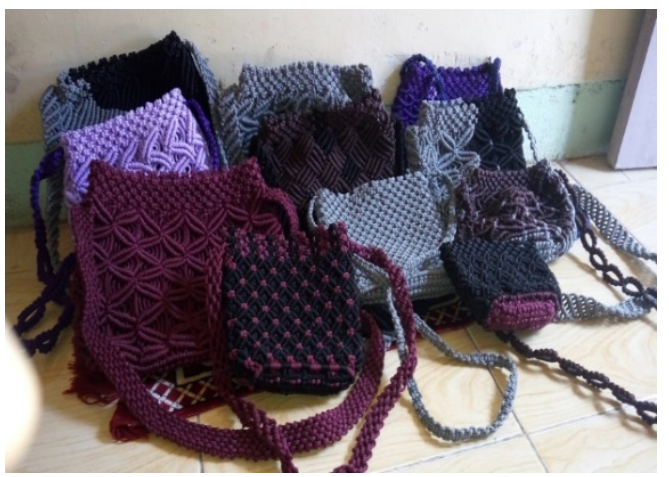

Gambar 4. Beberapa produk kerajinan tas

\section{Evaluasi Program}

Evaluasi program bertujuan untuk mengetahui tingkat pencapaian tujuan program pengabdian yang telah ditetapkan sebelumnya. Evaluasi dilakukan pada setiap tahapan kegiatan dengan menggunakan berbagai instrumen, diantaranya; lembar observasi pelaksanaan kegiatan, angket respon peserta pelatihan dan lembar penilaian kinerja. Hasil evaluasi pada setiap program menunjukkan hasil yang sesuai dengan tujuan program. Indikator keberhasilan pencapaian program 
meliputi (1) partisipasi remaja dalam mengikuti pelatihan (2) dukungan masyarakat sekitar terhadap seluruh rangkaian program sangat besar (3) remaja yang mengikuti pelatihan merasa sangat terbantu atas program yang telah dilaksanakan

\section{SIMPULAN DAN SARAN}

Program pengabdian yang telah dilaksanakan di desa Mambalan berhasil dan sesuai dengan tujuan program yang telah direncanakan sebelumnya. Adapun saran yang perlu diperhatikan oleh semua kalangan yaitu perlunya dukungan dari semua pihak terutama keluarga dan pemerintah dalam menanamkan keterampilan-keterampilan yang mampu menunjang kreativitas bagi anak-anak muda generasi penerus bangsa.

\section{UCAPAN TERIMAKASIH}

Ucapan terimaksih yang tinggi kepada;

1. LPPM UNDIKMA Mataram yang tiada henti memberikan bimbingan sehingga kegiatan ini dapat terlaksana dengan baik.

2. Masyarakat desa Mambalan yang memberikan ijin untuk terlaksananya kegiatan pengabdian.

\section{DAFTAR RUJUKAN}

Blanche, E.I. (2007). "The Expression of Creativity through Occupation." Journal of Occupational Science 14(1): pp. 2129.

Hosegood, B. (2009). "Whip Your Hobby into Shape: Knitting, Feminism, and Construction of Gender." Textile: The Journal of Cloth and Culture 7(2): pp.148-63.

Manuaba, IBG. (2009). Memahami Kesehatan Reproduksi. Arcan. Jakarta. 